This is the submitted version of the following article: Ruggieri, L., et al. Air filled porosity measurements by air pycnometry in the composting process: a review and a correlation analysis in Bioresource technology (Ed. Elsevier), vol. 100, issue 10 (May 2009), p. 2655-2666, which has been published in final form at DOI 10.1016/j.biortech.2008.12.049.

(c) 2008. This manuscript version is made available under the "all rights reserved" license. 


\section{Air filled porosity measurements by air pycnometry in the composting process: a review and a correlation analysis}

Luz Ruggieri, Teresa Gea, Adriana Artola and Antoni Sánchez*

Composting Research Group

Department of Chemical Engineering

Escola Tècnica Superior d'Enginyeria

Universitat Autònoma de Barcelona

Bellaterra (Cerdanyola, 08193-Barcelona, Spain)

* Corresponding author:

Dr. Antoni Sánchez

Phone: 34-935811019

Fax: 34-935812013

Email: antoni.sanchez@uab.cat 


\begin{abstract}
Air filled porosity (AFP) appears as the best measure to determine the available porosity in a composting material or, in general, in an organic matrix. Several methodologies, including theoretical and empirical approaches have been developed to estimate AFP. Among them, air pycnometry has been considered the most suitable and accurate technique to obtain reliable measures of AFP. In this review, the published methodologies to determine AFP by air pycnometry are explained in detail, and the main advantages and disadvantages of such methodologies are discussed. Also, a massive sampling of several organic wastes and mixtures intended for composting has been characterized by air pycnometry, and the theoretical and empirical correlations proposed in literature are compared in terms of accuracy in AFP measurement. Results obtained show that some theoretical correlations are suitable for estimating AFP in the majority of organic wastes studied. However, some waste samples need an experimental determination to obtain a realistic value of AFP.
\end{abstract}

Keywords: Air filled porosity, Composting, Free Air Space, Organic solid wastes, Pycnometry. 


\section{Introduction}

Composting is an aerobic biotechnological process by which different microbial communities initially degrade organic matter in solid substrates into simpler nutrients, carbon dioxide and water. In a second stage known as maturation, complex organic macromolecules such as humic acids are formed, producing an organic fertilizer named compost (Hsu and Lo, 1999). The process begins with the selection of the materials to be composted and several factors must be taken into account regarding the nature of these materials in order to obtain good quality compost. These factors are referred mostly to the physical properties that play an important role in every stage of compost production as well as in the handling and the utilization of the end product (Agnew and Leonard, 2003). The most studied physical properties of the composting materials are water content, water holding capacity, bulk density (BD), porosity $(\varepsilon)$ and air filled porosity (AFP, also known as free air space, FAS). These parameters depend on each other since the beginning of the process, and a deep knowledge of them is needed for a correct performance of the process. Water and oxygen content of a composting matrix are determining factors for the biological activity of the microorganisms involved and their availability is intrinsically related to the total and the AFP (Haug, 1993). The air content and air movement through the composting material is important to maintain an optimum oxygen concentration, to remove carbon dioxide and excess moisture, and to limit excessive heat accumulation (Haug, 1993). Maintaining adequate AFP levels satisfies the air content and pore continuity levels required to achieve desired composting conditions (Agnew et al., 2003).

As cited by Oppenheimer et al. (1997), there exist different methods for measuring solid matrix AFP like the specific gravity bottle, water retention apparatus, paraffin wax method and particle density method. All these methods are tedious and time consuming. Due to the 
fact that these methods were originally designed for soil characterization, they are non appropriate for solid wastes and compost AFP determination because they use few quantities of material, which usually does not provide a representative value for a heterogeneous composting matrix.

Other methods in use in the composting field are water pycnometry (Annan and White, 1998), and water saturation and draining procedures (U.S. Department of Agriculture and U.S. Compost Council, 1997); which were found to be more accurate than the methods mentioned above (Oppenheimer et al., 1997). Some negative implications of these methods have been described such as air entrapment (Annan and White, 1998), the fact that some substances can react or interact with water (Tamari, 2004) and the destruction of the sample during the analysis. On the contrary, the kerosene particle density methodology was developed for organic soils and avoids the swelling and the volume increase of organic particles that occurs in contact with water (Barrington et al., 2002). This method is precise although it presents some drawbacks such as the destruction of the sample, the manipulation of a harmful flammable substance and the generation of a hazardous waste.

Air pycnometry is considered, by a wide number of researchers, to be the most adequate methology for AFP determination in composting materials (Agnew and Leonard, 2003; Annan and White, 1998; Eftoda and McCartney, 2002; Oppenheimer et al., 1997; Su et al., 2006). Roughly, air pycnometry consists of applying Ideal Gas's law to indirectly measure the volume of the air voids within a solid matrix using air at a known pressure in a knownvolume sealed system.

The above mentioned limitations do not exist in air pycnometry. It has been demonstrated that the air pycnometry procedure does alter neither the physical properties nor the biological activity of the organic matrix (Berthe et al., 2007). Obviously, to obtain an accurate AFP 
measurement it is necessary to undertake a careful sampling and handling of the material and to proceed systematically according to am adequate protocol (Ruggieri, 2008).

The main goal of this work is to review the utilization of air pycnometry in the measurement of air filled porosity in the composting field. This is (i) to summarize the main issues related to air pycnometry methodology, (ii) to review the comparisons undertaken with other AFP measurements, (iii) to report theoretical and empirical relationships among AFP and other parameters and (iv) to review main cases and findings of AFP application in the experimental work on the composting field.

Moreover, a battery of experiments were run in order to corroborate all the reviewed information, and all obtained data was analysed with three purposes: (i) to compare AFP values empirically obtained by air pycnometry with AFP values obtained by theoretical approaches proposed by other authors, (ii) to compare AFP values empirically obtained by air pycnometry with values obtained by empirical approaches determined by other authors and (iii) to study the relationship between AFP obtained by air pycnometry and other physical parameters also experimentally determined.

\section{Air pycnometry}

\subsection{Involved Concepts: Porosity and Air Filled Porosity}

The concept of void volume, and related ideas such as porosity, void ratio and degree of saturation; have their origin in the science of soil mechanics. Both, concepts and nomenclatures, have been borrowed and applied to composting systems. Volume ratios commonly used in composting are the porosity and air filled porosity (AFP), also known as free air space (FAS). Porosity $(\varepsilon)$ of a composting mass is defined as the ratio of void volume 
of the sample $\left(\mathrm{V}_{\mathrm{v}}\right)$ to total volume of the sample $\left(\mathrm{V}_{\mathrm{s}}\right)$, including air and water filled voids as shown in Equation 1.

$\varepsilon=\frac{\mathrm{V}_{\mathrm{V}}}{\mathrm{V}_{\mathrm{s}}} \quad($ Equation 1$)$

On the other hand, AFP is defined as the ratio of air volume $\left(\mathrm{V}_{\mathrm{g}}\right)$ to total volume of the sample $\left(\mathrm{V}_{\mathrm{s}}\right)($ Haug, 1993) as presented in Equation 2.

$\mathrm{AFP}=\frac{\mathrm{V}_{\mathrm{g}}}{\mathrm{V}_{\mathrm{s}}} \quad$ (Equation 2)

Eftoda and McCartney (2002) proposed that the total volume of air in a composting matrix can be further divided into inter-particle and intra-particle air voids based on whether it is contained in interstitial voids between particles or in pore spaces within particles, respectively. They distinguished the first one as the readilly available air for aerobic microorganisms and named it free air space (FAS), on the other hand the intra-particle voids represent what they called unavailable air space (UAS) as it is not accessible to microorganisms.

According to these authors, the sum of both concepts FAS and UAS results in the total air space (TAS). The discussion on how to discriminate FAS and UAS from TAS has been discussed in previous studies (Agnew and Leonard, 2003; Eftoda and McCartney, 2002; Su et al., 2006) and it is explained below.

\subsection{Air pycnometer principle}

Air pycnometers provide indirect air space measurements by relating the system's pressures and volumes using the ideal Gas Law (Equation 3).

$\mathrm{PV}=\mathrm{nRT} \quad$ (Equation 3) 
where: $\mathrm{P}$, pressure $(\mathrm{kPa}) ; \mathrm{V}$, volume $(\mathrm{L}) ; \mathrm{n}$, moles of gas $(\mathrm{mol}) ; \mathrm{R}$, ideal gas constant $(8.2$ $\left.\mathrm{kPa} \mathrm{L} \mathrm{mol}{ }^{-1} \mathrm{~K}^{-1}\right) ; \mathrm{T}$, temperature (K).

The air pycnometer consists of a gas reservoir chamber $\left(\mathrm{V}_{\mathrm{gc}}\right)$ containing air at a known pressure $\left(\mathrm{P}_{1}\right)$ and a sample chamber $\left(\mathrm{V}_{\mathrm{sc}}\right)$ filled with a known volume of material $\left(\mathrm{V}_{\mathrm{s}}\right)$, yet initially opens to atmospheric pressure, and both connected by an air valve. After sealing the system, compressed air from the reservoir chamber is released to the sample chamber by opening the connecting valve and the pressure is allowed to equilibrate. A pressure gauge at the reservoir chamber registers the pressure before and after the connecting valve is opened. It is assumed that in a closed system with moderate pressures, as in the pycnometer, the temperature remains constant so the term nRT of the ideal gas law remains constant (Agnew and Leonard, 2002). Boyle's law can be used to derive the general equation for the pressure volume relationships under these two pressure regimes, by assuming that relative pressure in the reservoir chamber is initially zero. The resulting equation is presented below (Equation 4). $\mathrm{P}_{1} \mathrm{~V}_{\mathrm{gc}}=\mathrm{P}_{2} \mathrm{~V}_{\mathrm{t}} \quad($ Equation 4$)$

where: $\mathrm{P}_{1}$, initial pressure in compressed air vessel; $\mathrm{P}_{2}$, final pressure of equilibrated system; $\mathrm{V}_{\mathrm{gc}}$, volume of the compressed gas chamber; $\mathrm{V}_{\mathrm{t}}$, volume of overall system (compressed air chamber, air volume in sample chamber, pipes and fittings).

Equation 4 can be rearranged (by ignoring the air volume of fittings and pipes) producing the resulting Equation 5 for $\mathrm{V}_{\mathrm{g}}$.

$$
\mathrm{V}_{\mathrm{g}}=\frac{\left(\mathrm{P}_{1}-\mathrm{P}_{2}\right) \mathrm{V}_{\mathrm{gc}}}{\mathrm{P}_{2}} \quad \text { (Equation 5) }
$$

where: $\mathrm{V}_{\mathrm{g}}$, volume of gas air voids in the sample; $\mathrm{V}_{\mathrm{gc}}$, volume of the gas chamber; $\mathrm{P}_{1}$, initial pressure in the reservoir chamber and $\mathrm{P}_{2}$, the equilibrium pressure in the entire system. 
As mentioned before, AFP is expressed as the ratio of gas filled pore volume of the sample $\left(\mathrm{V}_{\mathrm{g}}\right)$ to total sample volume $\left(\mathrm{V}_{\mathrm{s}}\right)$. For AFP determination using an air pycnometer a theoretical relationship between AFP of the sample and the equilibrium pressure in the entire system $\left(\mathrm{P}_{2}\right)$ can be obtained by combining Equations 3, 4 and 5 and assuming that the exact volume of the air pycnometer is known, as shown in Equation 6.

$$
\mathrm{AFP}=\frac{\mathrm{V}_{\mathrm{g}}}{\mathrm{V}_{\mathrm{s}}}=\frac{\left(\mathrm{P}_{1}-\mathrm{P}_{2}\right) \mathrm{V}_{\mathrm{gc}}}{\mathrm{P}_{2} \mathrm{~V}_{\mathrm{s}}} \quad \text { (Equation 6) }
$$

On the other hand an empirical relationship of AFP with $\mathrm{P}_{2}$ can be obtained and used for the calibration of the system. A calibration curve can be generated by plotting the different $\mathrm{P}_{2}$ readings obtained for the different $\mathrm{V}_{\mathrm{s}}$ with a known AFP (as can be the resultant of adding successive water volumes to the sample chamber). The experimental data obtained will follow the expression in Equation 7 as well as the theoretical application of Equation 6.

$$
\mathrm{AFP}=\mathrm{a}+\frac{\mathrm{b}}{\mathrm{P}_{2}} \quad \text { (Equation 7) }
$$

where: AFP, air filled porosity; $\mathrm{P}_{2}$ equilibrium pressure of the entire system, $\mathrm{a}$ and $\mathrm{b}$, experimentally determined coefficients. The linear regression obtained (Equation 7) is used to compute AFP of the sample from the final gauge pressure reading. In relation to the hypothesis of considering ideal gases in air pycnometry, it can be concluded that, although there are some variations in the composition of gases during AFP measurement, no significant change in the number of moles is observed, as the respiratory quotient is around 1 (Gea et al., 2004). Moreover, the high amount of compressed air entering the system dilutes interstitial air and the resulting average composition is close to that of atmosphere. Hence, the gas behaviour can be described according to the ideal gases law. 


\subsection{Different pycnometers configuration}

Firstly it is important to distinguish references and vocabulary found in literature: air pycnometry, which uses ambient ordinary air, from gas pycnometry which can use any gas like helium or hydrogen. However, ordinary ambient air is the most commonly used gas in the composting field. There exist commercial air and gas pycnometers, but they are costly and too small to analyze representative samples of solid wastes (Agnew et al., 2003). For that reason, researchers on composting have been constructing self-made pycnometers. Table 1 summarizes the main characteristics of the pycnometers used for AFP determination in composting materials available in literature.

As Table 1 shows, the two main materials used are PVC and steel, as they are expected not to be deformed or expanded by the pressures in use. There are different sample chamber volumes reported, from $1 \mathrm{~L}$ to $45 \mathrm{~L}$ (Table 1). For composting materials AFP determination the volume of the sample chamber $\left(\mathrm{V}_{\mathrm{sc}}\right)$ must be as large as possible due to the intrinsic heterogeneity of the composting materials and to minimize the wall effect on the sample distribution and on the AFP measurement (McCartney and Chen, 2001). Various researchers used $\mathrm{V}_{\mathrm{sc}}$ lower than $1 \mathrm{~L}$, but they are usually referred to soil applications which are more homogeneous and of lower size distribution than composting materials. At this point it is important to distinguish initial and intermediate mixed materials to be composted from compost, where final compost, considered after improprieties or bulking agents sieving, is similar to soil in characteristics such as homogeneity and particle size. Also different $\mathrm{V}_{\mathrm{gc}}$ and $\mathrm{V}_{\text {sc }}$ relations have been reported, for instance Danielson and Sutherland (1986) recommended that the volume of $\mathrm{V}_{\mathrm{gc}}$ must be one third the $\mathrm{V}_{\mathrm{sc}}$, but these authors did not explain how they obtained their results; on the other hand Tamari (2004), based on a theoretical deduction, recommended to select an air chamber volume from one-third to two-thirds of the $\mathrm{V}_{\text {sc }}$. 
There is also a large range of initial pressures $\left(\mathrm{P}_{1}\right)$ reported, between 60 and $500 \mathrm{kPa}$. Agnew et al. (2003) believed that higher operating pressures result in more accurate readings, but extreme pressures require impractical designs. Regarding this, Agnew and Leonard (2002) established that an initial pressure of approximately $200 \mathrm{kPa}$ provides a good compromise between accuracy and practicality.

Moreover, an ongoing discussion is to establish a $\mathrm{P}_{1}$ value to ensure that what is being measured is the FAS and not the TAS. Su et al. (2006) compared results obtained by a commercial air pycnometer using a $\mathrm{P}_{1}$ of $134 \mathrm{kPa}$ with results obtained by a custom made pycnometer using a higher initial pressure (unspecified). Results showed that values obtained with the commercial air pycnometer were lower than values obtained by the custom made pycnometer, thus authors concluded that the lower initial pressure used with the commercial pycnometer "was believed to be the reason" that commercial pycnometer results represented FAS rather than TAS. For that reason authors recommended a further investigation to examine the impact of the initial pressure on air space readings. What is important to point out in this work is that the comparison of the two initial pressures used not only was made in two different pycnometers but also pycnometers had a significant difference related to the volume of the sample $\left(\mathrm{V}_{\mathrm{s}}\right)$ tested, being $0.15 \mathrm{~L}$ for the commercial air pycnometer and $20 \mathrm{~L}$ for the custom made pycnometer. This last factor is related to the representativeness of a heterogeneous matrix as composting matrices, where a small volume of the sample studied (like the commercial pycnometer with only $0.15 \mathrm{~L}$ ) is not considered a representative volume for this type of material.

Likewise, Agnew and Leonard (2002) reported that the associated pressures used in air pycnometry, and specifically the "high" pressure of $200 \mathrm{kPa}$ used in their custom made pycnometer could penetrate the intra-particle voids, and thus determine the TAS. Later, 
Agnew et al. (2003) stated that because of the pressures associated with air pycnometry in their study (from 70 to $200 \mathrm{kPa}$ ), all voids, including the micro pores within the particles, are penetrated. It is important to remark that these last two studies were performed by comparing AFP values obtained by air pycnometry versus AFP values obtained by other methods. This discussion is presented again in section 3.1 of this study.

For pycnometer calibration water is the most widely used material because the air dissolved on water can be considered negligible and because it is costless. However, some authors preferred known-volume materials like glass beads or steel ball bearings (Table 1).

A particular air pycnometer design is the one presented by McCartney and Chen (2001). In this case a piston is added to the sample chamber in order to simulate the compressive load of the different layers of material occurring at full-scale composting facilities. Weights are successively added to the piston to obtain the desired compression over the studied material sample. These authors observed clear differences among the obtained FAS values when different compressive loads were applied to the composting materials tested.

\subsection{Uncertainty analysis of the method}

Tamari (2004) studied the optimum design and working conditions of a constant volume gas pycnometer (the term includes air and gas pycnometer) for several applications, including wet soil samples and compost AFP determination (Agnew and Leonard, 2002). He related the pycnometer accuracy to the main sources of random error applying the law of propagation of uncertainty that was derived from a theoretical formula. With this study the author discarded three error sources: 1 . non-ideal gas behavior, 2. deformation of the pycnometers components, 3. pycnometers calibration. He also studied and marked as relevant: 4. gas pressure measurements, 5. non-isothermy of the system, 6. handling of pycnometers components, 7. 
gas leakage and transient effects. He concluded that to obtain the highest accuracy with a constant volume gas pycnometer, it is necessary to use an accurate absolute pressure transducer. The importance of using accurate pressure gauges and regulators was also highlighted as the factor yielding the greatest uncertainty in AFP by Oppenheimer et al. (1997). These authors also emphasized the need for accuracy in the air and sample chambers volume determinations. Oppenheimer et al. (1997) determined in their uncertainty analysis (using glass beads as volume referents) that an uncertainty in both chamber volume estimations leads to a significant uncertainty in AFP values, where as an example, $1 \%$ uncertainty in $\mathrm{V}_{\mathrm{gc}}$ or $\mathrm{V}_{\mathrm{sc}}$ leads to $3.9 \%$ uncertainty in AFP.

Furthermore, Tamari (2004) stated that a strict control of gas temperature during a test (e.g. within $\pm 0.02{ }^{\circ} \mathrm{C}$ ) is required. However, Agnew and Leonard (2003) found that temperature had no effect at any of the studied pressures, and that the higher pressure resulted in less variable final air pressure readings.

\section{Air pycnometry versus other AFP determination methodologies}

Several researchers have been investigating AFP determination in composting by air pycnometry and comparing their obtained results with values determined by other methods also used for composting materials such as water pycnometry or methods based on material density measurements. Experimental results have also been compared with those obtained from theoretical correlations which allow for AFP calculation as a function of physical and biological characteristics of the materials. The methods used and the results reported are summarized below and main remarkable issues are listed in Table 2. 


\subsection{Analytical techniques}

Different researchers compared AFP results obtained by air pycnometry with other analytical techniques which will be briefly described. In water pycnometry methodology (WP), a sample is submerged in a known volume of water and the volume of water needed to fill in air spaces within the material is considered as equal to the AFP volume. On the other hand, the water saturation and draining method (WS, U.S. Department of Agriculture and U.S. Compost Council, 1997) is based on the same principle but includes more steps. The sample is first saturated with water in a cylinder, the water is then allowed to drain from the bottom of the cylinder; and this procedure is repeated several times. The volume of air spaces is finally computed from the differences in weight between the saturated and drained states. Another method commonly used is the quick method (U.S. Department of Agriculture and U.S. Compost Council, 2001) which is the same as the water saturation and draining method but the sample is filled with water only once and will henceforth be referred with the same abbreviation, WS. Another group of methods in use are the ones based on particle density determination that were originally developed for soil analysis. The particle density is calculated as the mass of the particles divided by the volume they occupy, which includes the inter-particle voids. The traditional soil physic method (TSM) bases the porosity determination on empirical particle density measurements. During this process, the sample is boiled in water to purge any air present in the intra-particle voids. Su et al. (2006) considered that this method determines the total air space due to its aggressiveness. For measuring only the FAS, Eftoda and McCartney (2002) introduced an additional step to the traditional method proposed by Klute (1986), which is based on the mathematical models of Haug (1993) that consists of subtracting the volume of air contained within the unavailable air space (UAS). They named the method "modified particle density method (MPD)". 
In general, these methods have shown high precision and repeatability (Agnew and Leonard, 2003; Su et al., 2006). However, they lead to statistically different quantification of AFP although a certain relationship with air pycnometry has been shown (Annan and White, 1998; Su et al., 2006).

WP and WS methods presented several drawbacks because they modified the sample structure due to particle reorientation (Eftoda and McCartney, 2002; Su et al., 2006) and made repetitive analysis difficult (Agnew and Leonard, 2003). Additional problems have been reported related to the difficulty of sample drainage (Annan and White, 1998; Su et al., 2006). On the other hand, the AFP measurements obtained by air pycnometry were usually higher than those obtained with WP or WS methods. This has been explained as the result of pressurised air ability to penetrate all voids, including micropores, which water would not reach (Agnew and Leonard, 2003; Eftoda and McCartney, 2002), because of the high viscosity of water. Also air entrapment when adding water to the sample in WP and WS methods resulted in the underestimation of AFP.

On the other hand, TSM method yielded higher values than air pycnometry and WP (Su et al., 2006) probably due to the inclusion of closed pore spaces which were excluded by the other methodologies.

The results obtained by different authors concluded that air pycnometry was the best method of choice because it is simple, repeatable and fast. It also measures more accurately the numerous small pore spaces found in any compost sample (Annan and White, 1998).

\subsection{Theoretical approaches}

Table 3 summarizes the different theoretical approaches developed by several authors, considering the physical relationship of porosity $(\varepsilon)$ with other parameters like bulk density 
(BD), particle density (PD) and moisture (MC) and organic matter content (OM). Among them, the simplest approach is the one presented by Epstein (1997) (Equation 8, Table 3). This equation has been used to estimate FAS values in recent studies whose main objective was the determination of the effectiveness of bulking agents and mixtures of organic wastes proposed for the improvement of the composting process performance (Adhikari et al., 2008; Kulcu et al., 2008; Vlyssides et al., 2008).

In general, all these equations have been proved to provide good estimations of AFP which correlate well with measurements by air pycnometry (Annan and White, 1998; Richard et al., 2004). On the other hand Oppenheimer et al. (1997) demonstrated the existence of a linear relationship between AFP and moisture content (dry basis) using as experimental materials a mixture of dog food and wood chips. Differences between empirical and theoretical equations have been quantified to be around 3-6\% (Ahn et al., 2008; Berthe et al., 2007) which might be considered an acceptable discrepancy. The main drawback associated with the use of these equations is that some of the required parameters, like specific gravity or particle density, are difficult to determine. Equation 9 (Table 3), proposed by Richard et al. (2004) as an adaptation from Tarzaghi's theory of primary compression (Tarzaghi et al., 1996), might be one of the most valid expressions because it allows for the estimation of AFP from routinely determined parameters like $\mathrm{MC}, \mathrm{OM}$ and $\mathrm{BD}$, and from constant values for particle density of the different fractions (water, organic matter and ash, Table 3).

\section{Empirical relationships for AFP with different physical and biological}

\section{parameters}

Some authors have investigated AFP measurements by air pycnometry and have tried to develop empirical relationships between AFP and different physical and biological 
parameters. Parameters such as oxygen availability, moisture content (MC) and process temperature are related to several physical parameters like AFP, porosity $(\varepsilon)$, bulk density (BD), permeability and mechanical strength, among others (Richard et al., 2004). The former parameters are often selected as the control variables in the composting process together with other biochemical and microbiological properties (Haug, 1993). The biological parameters most widely used in the composting field are the temperature and the respirometric indices which measure $\mathrm{CO}_{2}$ evolution or $\mathrm{O}_{2}$ consumption during the degradation process (Barrena et al., 2006). The index most widely used is the oxygen uptake rate (OUR) that expresses the velocity of $\mathrm{O}_{2}$ consumption (usually expressed as $\mathrm{mg} \mathrm{O}_{2} \mathrm{~g} \mathrm{OM}^{-1} \mathrm{~h}^{-1}$ ).

\subsection{Relationships of AFP with moisture content and bulk density}

The most relevant equations obtained by different authors correlating AFP with moisture content and bulk density are summarized in Table 4 and discussed below.

Considering the experimental results reported it could be concluded that the AFP of a compost mixture tends to decrease linearly with $\mathrm{MC}(\mathrm{db})$ but non-linearly with $\mathrm{MC}(\mathrm{wb})$ (Agnew and Leonard, 2003). However, other authors have linearly correlated theoretical values of AFP with MC (db) (Oppenheimer et al., 1997) and MC (wb) (Madejon et al., 2002).

The relationship of AFP with wet bulk density $\left(\mathrm{BD}_{\mathrm{w}}\right)$ is the most frequently described one. Agnew and Leonard (2002) found linear relationships between AFP and wet bulk density for different organic materials (Table 4). It is interesting to note the similarity between the values of the coefficients for the different materials tested. For instance, when comparing MSW and manure compost, the AFP in MSW was slightly lower because the magnitude of the $\mathrm{BD}_{\mathrm{w}}$ was slightly higher in MSW than in manure. The particle size of the MSW was smaller than the manure compost one, making a slightly denser and more compact material. In addition, the 
particle sizes were more uniform and as a consequence the large pore spaces were eliminated. Based on these results they suggested that one equation could describe the $\mathrm{AFP}$ and $\mathrm{BD}_{\mathrm{w}}$ relationship for all composting materials (Equation 13, Table 4), with a regression coefficient, $\mathrm{R}^{2}$, of 0.97 . This equation was found to be valid for materials with moisture content levels below $80 \%$. Richard et al. (2004) also established that the experimental results obtained by pycnometry and the theoretical predictions fit well with the relationship between AFP and $\mathrm{BD}_{\mathrm{w}}$ proposed by Agnew and Leonard (2002). However, a significant effect of the dry matter (DM) content on this relationship was found in their theoretical analysis, which on the other hand is not evident in the empirical analysis. Regarding this, although the theoretical analysis is consistent with Agnew and Leonard (2002) equations in the high moisture and/or low density region, it was observed a significant deviation outside these regions when compared with experimental data (Richard et al., 2004). Equation 9 (Table 3) appears to provide an accurate way of predicting air-filled porosity for the full range of MC usual in composting materials, subject to verification of the component densities for other substrate matrices.

On the other hand Mohee and Mudhoo (2005) found that AFP, measured using water pycnometry methodology, varied linearly with both $\mathrm{BD}_{\mathrm{w}}\left(\mathrm{R}^{2}=0.89\right)$ and $\mathrm{BD}_{\mathrm{d}}\left(\mathrm{R}^{2}=0.95\right)$ for the studied materials (chicken manure, woodchip, mixed green vegetables), as shown in Equations 15 and 16 (Table 4). However, while the linear relationship between AFP and BD was well defined, the AFP-MC (wb) profile followed a fourth degree polynomial trend with a correlation coefficient of only 0.63 .

Ahn et al. (2008) investigated the physical parameters for a broad variety of potential mortality composting cover materials for a large scale composting process. The objective of their work was to develop a general relationship within airflow characteristics, i.e., permeability and AFP determined by air pycnometry, to varying moisture contents and 
degrees of compaction. As expected, authors concluded that AFP decreased with increasing bulk density, moisture content and compost depth for all materials. Similarly permeability decreased with increasing compost depth but it did show a complex relationship with moisture content. McCartney and Chen (2001) made an extensive study about compost compressive load and determined an empirical formula based on the vertical bulk density and AFP profiles of a compost pile. The resulting equation is shown in Table 4 (Equation 17). The data obtained for different composting materials were in very good agreement with this equation, with all $\mathrm{R}^{2}$ greater than 0.988 .

\subsection{Relationships of AFP with other parameters}

Agnew and Leonard (2003) cited a comparison of porosity versus AFP made by other authors indicating a highly correlated linear relationship between AFP and the relative oxygen diffusion rate at four different depths in ground domestic garbage compost with an $\mathrm{R}^{2}=0.94$ 0.99 for AFP values ranging from 22 to $44.5 \%$. They discussed about the importance of the diffusion factor stating that it has not a key importance in the transfer of oxygen within the compost matrix for large-scale operation and concluding that free or forced convection of air is of greater importance. AFP should provide some measure of the ease with which these mechanisms can transfer oxygen through compost.

For predicting permeability as a function of AFP and particle size, Richard et al. (2004) based their study on Kozeny-Carmen analysis. Increasing of permeability with increasing AFP and decreasing BD is intuitive, but what authors remark as interesting, is that the reduction in AFP that accompanies increasing moisture content (MC) coincides with an increase in permeability, up to almost saturation. This appears to be related to changes in particle and pore size distribution as moisture facilitates the aggregation of fines into fewer 
larger particles with corresponding larger intraparticle pores. The same relationship was observed by Poulsen and Moldrup (2007) in his theoretical study.

In their work, Oppenheimer et al. (1997) found no correlations between AFP and particle size, but they attributed this to both the limited wood chip size range and the formation of undefined aggregates inside the studied materials. On the contrary, Barrington et al. (2002) correlated several physical parameters related to airflow resistance such as bulk density, depth of material, pressure drop and FAS, which in this study is called void ratio. This void ratio was measured by the kerosene dry particle density method (Barrington et al., 2002). It is interesting to note that these authors found different correlations for fresh and old compost.

Eftoda and McCartney (2002) related AFP to biological parameters like pathogen reduction and maturity as oxygen uptake rate (OUR), for biosolids with woodchip mixtures. It was found that both maturity and temperature were strongly correlated to AFP. However pathogen reduction was not. This last fact was attributed to the absence of a significant thermophilic period in any of the test. For biological comparison a trend of increasing stability with AFP ranging between $27.4 \%$ and $47.1 \%$ was found in the range of runs tested and hence corresponded to increasing maturity with increasing initial AFP content, with an $\mathrm{R}^{2}$ $=0.8812$. Berthe et al. (2007) coupled a respirometer to an air pycnometer and found that initial AFP values between $41 \%$ and $70 \%$ were never limiting the biological processes -also measured as OUR-. On the other hand initial values of $23 \%$ affected the biological activity and an addition of a bulking agent was necessary to increase AFP to an adequate value, which resulted also in a decrease of moisture content. These results have been also observed in other recent works (Ruggieri et al., 2008a). Finally, Yu et al. (2008) have recently presented an exhaustive study about the FAS influence on microbial kinetics in passively aerated compost. In this work, a sigmoid relationship was found among FAS and the maximum degradation 
rate achieved in the composting of manure for a FAS range of values of 0.35 to 0.65 , which were determined by air pycnometry. These authors also propose a model in which FAS is included to estimate kinetic constants. Other complex composting models such as the integrated physical and biochemical model developed by Sole-Mauri et al. (2007) and the physical model proposed to describe pile settlement by Yue et al., (2008) also incorporate porosity as a physical parameter in the mathematical model.

\section{Determining optimal AFP values for the composting process}

Physical characteristics of the initial mixture are decisive in the composting process (Ruggieri et al., 2008b). As mentioned before, AFP is considered one of the most important physical characteristics not only for the initial composting mixture but also throughout the process, since adequate air spaces are needed to provide oxygen to aerobic bacteria. Insufficient AFP can prolong the composting period and may lead to anaerobic conditions (Annan and White, 1998). Most of the data found do not discriminate between recommended initial values and optimum process values. There is a wide range of reported values and all seem to be dependent of the type of material to be composted. Usually publications report AFP values that yield the highest biological activity per organic mass unit.

Some models include AFP as an input parameter. Haug (1993) presented an inductive model based on the observation of the existence of a limited AFP range ( $>30 \%)$ that could sustain high activities (expressed as OUR) in the optimal moisture range as shown in Equation 18:

$\operatorname{OUR}\left(\mathrm{V}_{\mathrm{g}}\right)=\mathrm{F}\left(\mathrm{V}_{\mathrm{g}}\right)$ OUR max,c

(Equation 18)

where

$F\left(V_{g}\right)=\frac{1}{e^{\left(-23.675 V_{g}+3.4945\right)}+1}$ 
where: $\mathrm{V}_{\mathrm{g}}$, relative volume of gas; $\mathrm{F}$, restriction factor of the inductive model; OUR max,c, maximum OUR of the feed material, for a given volume of sample.

Although Haug (1993) was perfectly aware of the dependences between AFP and DM via the solids volume fraction, the model treated the solids volume fraction and the particle water volume as independent variables. Hamelers and Richard (2001) presented a mechanistic model that described the relation between microbial activity and gases, liquid, and solid volume. Based on the theory of particle level (Hamelers, 1993), the oxygen consumption was considered dependent on the surface area of the aggregates and an equation for OUR during start up was determined. Based on the deductive model they estimated how the biological activity changed with free air space. This model can be used to calculate the free air space required for a good start up of the composting process. First they estimated the OUR by the heat balance and then compared results with AFP between 20-40\%. The bed, however, had to remain stable throughout the run and the results showed how the weakening of the bed structure with increasing temperature was a greater problem than the accurate estimation of the volume of free air space required. They finally concluded that both empirical and deductive models describe the effect of AFP on composting activity in a similar satisfying way, as AFP is the limiting factor during start up of the composting of wet manure. Authors remarked that in mechanistic models fewer parameters are used. Rudrum et al. (2002) developed a deductive model and focused their research on constructing a bed that will generate enough activity to finish the composting process in three weeks.

Regarding optimal AFP values recommended for the composting process, firstly Jeris and Regan (1973) concluded that an AFP of 30-36\% is required to obtain optimum composting conditions by estimating the consumption of oxygen required for the composting of a wide 
variety of residues with different MC. Furthermore, Haug (1993) cited various historical studies that suggested that an AFP of at least $20 \%$ was required for composting systems. After that Annan and White (1998) made an extensive research and reported that the optimum level of AFP for composting is between 30-60\%. On the other hand, Ahn et al. (2008) cited that previous researchers have reported that the optimum and minimum range of porosity for aerobic decomposition was $85-90 \%$ and $30 \%$ respectively. Michel et al. (2004) found that an initial AFP higher than $75 \%$-tested in four different runnings- was excessive to achieve thermophilic temperatures when composting dairy manure, while values below $65 \%$ were appropriated for the correct performance of the composting process for the same substrate.

Ruggieri et al. (2008b) studied the levels of AFP during three co-composting experiments of biosolids plus different biochemical amendments and one composting control experiment (biosolids alone). Initial AFP was adjusted to $40 \%$ for all runs and was found to be a good compromise value for the correct performance of all processes. AFP tended to decrease during the thermophilic period and to increase at the end of the co-composting process when biochemical amendments were present, but this was not observed in the control experiment. Authors related this fact to the higher percentages of organic matter degradation obtained in all the co-composting processes compared to the control experiment. The relationship among the AFP evolution and the biodegradable organic matter content of the composting wastes was confirmed when studying the process performance for raw and digested sludge (Ruggieri et al., 2008a). Minimum AFP requirements were established at 35\% while maximum AFP levels recommended in order to avoid heat losses varied according to the wastes composition: $45 \%$ was excessive for wastes with low biodegradable organic matter content while highly biodegradable materials were successfully composted at AFP levels of $68 \%$. On the other hand Richard and Byung (2003) did not find any significant variation of AFP measured but a 
slightly increase during the process, from 61 to $63 \%$ and 61 to $67 \%$ in nine weeks composting process time. As mentioned before, Berthe et al. (2007) stated that values between $41 \%$ and $70 \%$ were never limiting the biological processes for different composting materials, but an initial value of $23 \%$ resulted insufficient for the microorganisms activity. They also concluded that the AFP determination at the beginning and at the end of the respirometry did not reveal a clear profile for the test and that the variation in AFP remained within the precision of the method. Other recent study has reported an optimal FAS value of $33 \%$ in the composting of goat manure and wheat straw (Kulcu and Yaldiz, 2007). These authors also report other study in which similar values of optimal FAS have been obtained with grass and leaf wastes.

Eftoda and McCartney (2004) tried to determine what they called critical bulking agent requirement (CBAR) for composting. The CBAR is defined as the minimum amount of bulking agent required to maintain adequate pore space oxygen levels in the compost matrix. For calculating AFP they used the traditional soil physic methodology with and additional step to determine the AFP, as explained before. CBAR, based on a target AFP over $20 \%$ and minimum pore space oxygen over 5\%, were 1:2.5 and 1:2.8 (biosolids: wood chips; vol:vol), respectively.

\section{Air Filled Porosity correlation analysis}

The objective of this section is to test some of the theoretical and empirical correlations proposed by different researchers for AFP determination (Table 3 and Table 4), by comparing the AFP values obtained using these correlations, with those experimentally measured by air pycnometry. The applicability of the proposed equations was tested for a broad type of materials. In addition AFP empirical data have been also correlated to other physical properties of the composting materials. 


\subsection{Materials and Methods}

Table 5 shows AFP values and the main physical characteristics of the composting materials under study. AFP measurements were undertaken by a custom-made constant air pycnometer made of stainless steel with a sample and an air chamber volume of $21 \mathrm{~L}$, and a sample cup volume of $14.85 \mathrm{~L}$. Used initial pressures ranged from 300 to $500 \mathrm{kPa}$. AFP values are presented as the average of three replicates.

Correlations were identified and calculated for the best curve fit using the software Sigma Plot 8.1 (2006, SPSS Inc.). The software SPSS 15.1 (2006, SPSS Inc.) was used for the statistical analysis presented in this section. Two methodologies were used for the analyses presented, Paired Sample Correlation and Univariate General Linear model data analyses.

\subsection{Comparing AFP obtained by air pycnometry with a theoretical approach}

In this section AFP values obtained by air pycnometry $\left(\mathrm{AFP}_{\mathrm{P}}\right)$ were compared with results obtained by the theoretical AFP relationship established by Richard et al. (2004) ( $\mathrm{AFP}_{\mathrm{R}}$ ) and presented as Equation 9 in Table 3. AFP mean values, for all composting materials under study, were: $\mathrm{AFP}_{\mathrm{P}}=0.584$ and $\mathrm{AFP}_{\mathrm{R}}=0.592$. Although $\mathrm{AFP}_{\mathrm{R}}$ was slightly higher than $\mathrm{AFP}_{\mathrm{P}}$, as previously observed (Ahn et al., 2008; Richard et al., 2004), the statistical analysis concluded that there were no significant differences between both parameters. The 95\% confidence interval of the differences was from -0.026 to 0.010 . AFPP and $\mathrm{AFP}_{\mathrm{R}}$ were linearly correlated for all materials under study as shown in Figure 1 . The resulting equation is $\mathrm{AFP}=$ $0.0273+0.917 \mathrm{AFP}_{\mathrm{R}}$ with an $\mathrm{R}^{2}$ value of 0.926 and $\mathrm{p}<0.0001$. Moreover, if $\mathrm{AFP}_{\mathrm{R}}$ method is compared with $\mathrm{AFP}_{\mathrm{P}}$ method the mean absolute difference is 0.038 . 
As can be observed in Figure 1, points that presented a higher deviation from the correlation line are those corresponding to wood chips (WC), stalk (ST) and organic fraction of the municipal solid waste (OFMSW), which are in the higher AFP range. These points correspond mostly to samples presenting the lowest DM content, ranging between $20-45 \%$. Richard et al. (2004) observed a similar behaviour when comparing AFP values obtained by the theoretical approach expressed in Equation 9 (Table 3) with an empirical analysis and attributed this to a significant effect of the dry matter content on the theoretical relationship, which is not evident in the empirical analysis. On the other hand, other materials having similar DM content (Table 5) are nearest to the regression curve, which would mean that the DM content is not the only factor affecting this theoretical relationship. As can also be observed in Table 5, BD values of wood chips (WC), stalk (ST) and OFMSW are the lowest if compared with BD values of all the other materials. Regarding this last observation, it can be concluded that the theoretical approach proposed by Richard et al. (2004) seems to be more influenced by the BD of the materials under study than from its DM content.

\subsection{Comparing AFP obtained by air pycnometry with other empirical approaches}

Values obtained by air pycnometry were also compared with results obtained by empirical relationships for AFP determination established by Agnew and Leonard (2002) ( $\mathrm{AFP}_{\mathrm{AL}}$ ), Liao et al. (1993) ( $\left.\mathrm{AFP}_{\mathrm{L}}\right)$ and Mohee and Mudhoo (2005) (AFP $\mathrm{MM}_{\mathrm{M}}$. The used equations were 13, 14 and 15 respectively (Table 4).

$\mathrm{AFP}_{\mathrm{P}}$ and $\mathrm{AFP}_{\mathrm{AL}}$ were linearly correlated for all materials under study. The obtained equation and the statistical study result are shown in Table 6. The obtained mean value for $\mathrm{AFP}_{\mathrm{AL}}$ was 0.494 , the correlation obtained between both was statistically significant. The confidence interval of the differences ranged between 0.07 and 0.10 . As observed when 
comparing $\mathrm{AFP}_{\mathrm{P}}$ and $\mathrm{AFP}_{\mathrm{R}}$ theoretical approach, samples corresponding to materials with low DM content as OFMSW and ST appeared far from the correlation line. But in this correlation analysis other points appeared far from the regression curve if compared with points plotted at Figure 1. These points correspond to samples of materials that also presented low DM content, but $\mathrm{BD}$ values over $0.5 \mathrm{~kg} / \mathrm{L}$, where samples pointed out as conflictive in Figure 1 had BD values inferior to $0.4 \mathrm{~kg} / \mathrm{L}$. Therefore, from this particular correlation analysis, it can be concluded that the empirical approach proposed by Agnew and Leonard (2002), seems to be more sensitive to BD values if compared to the Richard et al. (2004) approach. This observation is in agreement with a previous Richard et al. (2004) finding, where the authors stated that Agnew and Leonard's equation should only be applied in high-moisture and/or low-density region where their relationship appears applicable.

If $\mathrm{AFP}_{\mathrm{R}}$ is plotted versus $\mathrm{AFP}_{\mathrm{AL}}$, the linear relationship fits better than both those from correlation analysis previously studied, with the resulting equation shown in Table 6. A high correlation is obtained with a $\mathrm{R}^{2}$ of 0.988 , with a $95 \%$ confidence interval of the differences that ranged between 0.09 and 0.10 . Richard et al. (2004) found the same $\mathrm{R}^{2}$ when comparing their $\mathrm{AFP}_{\mathrm{R}}$ values obtained by the theoretical approach versus values determined by empirical $\mathrm{AFP}_{\mathrm{AL}}$. When comparing $\mathrm{AFP}_{\mathrm{R}}$ versus $\mathrm{AFP}_{\mathrm{AL}}$, the dispersion observed for the same critical samples in the former two correlation analysis is not so pronounced. This behaviour is confirming $\mathrm{AFP}_{\mathrm{P}}$ as the most adequate technique for determining the AFP of all types of materials, as the weakness of both approaches is related to the same physical parameters. Likewise, Mohee and Mudhoo (2005) proposed an empirical relationship, which is much similar to Agnew and Leonard's equation (Table 6). AFP ${ }_{\text {MM }}$ obtained mean value was 0.532 , all values highly correlated with $\mathrm{AFP}_{\mathrm{P}}$ values as shown in Table 6, with a 95\% confidence interval difference that ranged between 0.032 and 0.71 . Once again, values fastest from the 
correlation line correspond to the same conflict samples as previously observed when compared $\mathrm{AFP}_{\mathrm{P}}$ versus $\mathrm{AFP}_{\mathrm{AL}}$. Therefore, the same restriction on using Agnew and Leonard's equation is applicable to the empirical relationship proposed by Mohee and Mudhoo (2005).

$\mathrm{AFP}$ and $\mathrm{AFP}_{\mathrm{L}}$ relationship was fitted to a linear regression for all materials under study, the resulted equation is shown in Table 6. The mean value obtained for this approach was 0.824, which was much higher than all mean values obtained with the other approaches. The obtained correlation curve and coefficients are shown in Table 6. A clear relationship was not observed between $\mathrm{AFP}_{\mathrm{P}}$ and $\mathrm{AFP}_{\mathrm{L}}$, being more notorious with higher $\mathrm{AFP}$ values. It is important to remark that the equation presented by Liao et al. (1993) is expressed as a function of MC. Values that are closer to the regression line are those corresponding to materials with MC lower than 65\% (OFMSW and WC) which does not coincide with the MC of the swine manure (50-80\%) from which the authors brought this empirical relationship. For reasons discussed before, Liao et al.'s empirical approach is not recommended for AFP determination of composting materials.

\subsection{Correlating AFP obtained by air pycnometry with other physical parameters}

This section summarises some empirical relationships established between the AFP values that were determined by air pycnometry $\left(\mathrm{AFP}_{\mathrm{P}}\right)$ and other process parameters that were determined at the same time as the run experiments in order to study the composting process performance (values shown in Table 5).

The relationship between $\mathrm{AFP}$ and $\mathrm{BD}_{\mathrm{w}}$ is the most frequently studied. This parameter was always found to linearly correlate with AFP for a broad type of materials. Figure 2 shows the linear relationship between $\mathrm{AFP}_{\mathrm{P}}$ and $\mathrm{BD}_{\mathrm{w}}$ for all the studied materials. The resulted equation was $\mathrm{AFP}_{\mathrm{P}}=1.00-0.8844 \mathrm{BD}_{\mathrm{w}}$ with a $\mathrm{R}^{2}$ of 0.982 and $\mathrm{p}<0.0001$. These coefficients corroborate 
the linearity observed by other authors. In fact Agnew and Leonard (2002) found very similar coefficients as reviewed before. Likewise, if AFP values obtained by the $\mathrm{BD}_{\mathrm{w}}$ correlation are compared with AFP values obtained by air pycnometry, the mean absolute error for the $\mathrm{BD}_{\mathrm{w}}$ method utilization is 0.048 .

On the other hand, if the data plotted in Figure 2 is separated in two groups on the basis of the DM content of the studied materials and a linear correlation is adjusted for each group, the obtained lines show a different behaviour as can be also seen in Figure 2. From this analysis it can be deduced that a slight effect of dry matter also exists on the empirical analysis, but is not so marked as that one found for the $\mathrm{AFP}_{\mathrm{R}}$ or $\mathrm{AFP}_{\mathrm{AL}}$ approaches. When materials with low $\mathrm{DM}$ are represented, the relationship between $\mathrm{AFP}_{\mathrm{P}}$ and $\mathrm{BD}_{\mathrm{w}}$ shows a high $\mathrm{R}^{2}$ of 0.98 , but when materials with higher DM are plotted, this $\mathrm{R}^{2}$ is not so good $(0.8)$ as shown in Figure 2.

Likewise, if values of $\mathrm{AFP}$ are plotted versus bulk density $\left(\mathrm{BD}_{\mathrm{d}}\right)$ expressed in dry basis $(\mathrm{db})$, the obtained equation for this plot is $\mathrm{AFP}_{\mathrm{P}}=1.003-2.899 \mathrm{BD}_{\mathrm{d}}$, with $\mathrm{R}^{2}$ values of 0.5 . In contradiction with Oppenheimer et al. (1997), who found a clear relationship when considering a mixture of sewage sludge and woodchips, correlation between AFP and $\mathrm{BD}_{\mathrm{d}}$ for a broad type of materials did not show a clear relationship.

Madejón et al. (2002) determined the AFP of their studied materials by Equation 11 (Table 3). The authors established a relationship between AFP and MC (\%), which resulted in a polynomial 4th degree, with an $\mathrm{R}^{2}=0.63$. Likewise, Richard et al. (2004) and Oppenheimer et al. (1997) found a linear correlation between AFP and MC, for the same materials with the particularity that all materials under study had a constant BD.

On the contrary, all materials under study in this section had a wide range of BD as can be seen in Table 5. For that reason it was impossible to establish a clear relationship between these two studied parameters (MC and AFP). On the other hand, as intuitively expected, a 
general trend of decreasing AFP (\%) with increasing MC (\%) was observed, as the water might be occupying the air voids. However, the regression curve obtained for all materials under study had a $\mathrm{R}^{2}$ of 0.466 , which indicated that it is impossible to calculate AFP values for all kind of materials only from the material MC, which was also previously observed in section 6.3.

Richard et al.'s (2004) theoretical approach, which includes the correlation of all these parameters, correlated well with all the other empirical approaches presented in this study with $\mathrm{R}^{2}>0.9$. Regarding this fact, this theoretical approach (which has been corroborated by the comparison with valid empirical approaches) is proposed as the most accurate for correlating AFP with DM, OM and BD for all type of composting materials.

\section{Conclusions and final remarks}

Air pycnometry is pointed by different authors as the most reliable technique for air filled porosity determination in composting processes. The main advantages when compared with other methods are:

- $\quad$ Compressed air has the ability to penetrate all voids, including micropores, in a solid sample.

- Air pycnometry allows for the use of large samples and thus enhances representativeness of the measurement.

- The measurement does not change the structure of the material and the sample is not destroyed.

- $\quad$ Theoretical approaches usually require previous knowledge of some parameters that are difficult or tedious to determine. 
The main disadvantage is that no commercial equipment is available. However air pycnometers are simple devices which can be easily built at reasonable cost.

Empirical equations have been developed that correlate air filled porosity and different physical and biological parameters. Linear correlations for air filled porosity and wet and dry bulk density have been presented for different materials. Permeability, oxygen diffusion rate and oxygen uptake rate have also been studied.

Minimum values for initial air filled porosity in a composting process to ensure biological activity have been reported at 30\% (Haug, 1993; Jeris and Reagan, 1973) while values over $60-70 \%$ seem to be excessive to achieve thermophilic temperatures in wastes with low biodegradable organic matter content. On the other hand, it is not clearly stated in literature if the AFP values proposed as optimal corresponded to initial mixtures or to those to be maintained throughout the composting process. Physical characteristics of the compost obtained should be considered in accordance to the further utilization of this material.

In relation to the correlation analysis of AFP, it can be concluded that:

Air pycnometry is the most adequate technique for AFP determination of all types of composting material, independent of specific characteristic (as BD and DM) of some materials, which on the other hand, do influence the AFP determination by other theoretical and empirical approaches.

- The theoretical approach proposed by Richard et al. (2004) seems to be more influenced by the BD of the materials under study than from its DM content. Special attention must be given to materials with $\mathrm{BD}$ values lower than $0.4 \mathrm{~kg} / \mathrm{L}$, where Richard et al.'s equation might be disturbing AFP values.

- $\quad$ The empirical approach of Agnew and Leonard (2002) resulted to be also dependent of BD values, where low values (under $0.4 \mathrm{~kg} / \mathrm{L}$ ) may lead to erroneous AFP values. 
This approach has also demonstrated that it is DM dependent, therefore it might also be only applied for materials with $\mathrm{DM}<50 \%$. Agnew and Leonard's equation should only be applied in high-moisture and/or low-density region where their relationship appears applicable.

- Wet Bulk Density was found to be the physical parameter that better correlate with AFP, presenting $\mathrm{R}^{2}>0.9$ in all cases. On the other hand, both empirical approaches that only include BD for AFP determination were also found to be much appropriated. Values determined by both approaches presented a high correlation with values obtained by air pycnometry with $\mathrm{R}^{2}>0.89$.

Finally, when evaluating AFP determination techniques for composting materials, the preference order must be:

- $\quad$ Firstly, air pycnometry, as it was demonstrated to be the most accurate technique.

- If researchers do not have a custom made pycnometer available in their laboratories, the second choice would be Richard et al.`s equation, but special attention must be taken regarding its previously reported limitations.

- $\quad$ For a rapid determination, both Agnew and Leonard`s and Mohee and Mudhoo`s equation could be used as a third choice also taking into account the previously mentioned limitations.

\section{Acknowledgements}

The authors wish to thank the financial support provided by the Spanish Ministerio de Ciencia y Tecnología (Project CTM2006-00315) 


\section{References}

Adhikari, B.K., Barrington, S., Martinez, J., King, S., 2008. Effectiveness of three bulking agents for food waste composting. Waste Manage. in press: doi:10.1016/j.wasman.2008.04.001

Agnew, J.M., Leonard, J.J., 2002. Using a modified pycnometer to determine free air space and bulk density of compost mixture while simulating compressive loading, in: Michel, F.C., Rynk, R.F., Hoiting, H.A.J. (Eds), Proceedings of the International Symposium Composting and Compost Utilization, Columbus, Ohio, USA, pp. 183204.

Agnew, J.M., Leonard, J.J., 2003. Literature review. The physical properties of compost. Compost Sci. Util. 11, 238-264.

Agnew, J.M., Leonard, J. J., Feddes, J., Feng Y., 2003. A modified air pycnometer for compost volume and density determination. Canadian Biosystem Eng. 45, 27-34.

Ahn, K.K, Richard, T.L., Glanville, T. D., 2008. Laboratory determination of compost physical parameters for modeling of airflow characteristics. Waste Manage. 28, 660670.

Annan, J. S., White, R. K., 1998. Evaluation of techniques for measuring air filled- porosity in composts of municipal biosolids and wood chips, in: Das, K.C., Graves E.F. (Eds), Composting in the Southeast-Proceedings of the 1998 Conference, South Carolina, USA, pp. 88-96.

Barrena, R., Vázquez, F., Sánchez, A., 2006. The Use of Respiration Indices in the Composting Process: A Review. Waste Manage. Res. 24, 37-47.

Barrington, S., Choinière, D., Trigui, M., Knight, W., 2002. Compost Airflow Resistance. Biosystems Eng. 81, 433-441. 
Berthe, L., Druilhe, C., Massiani, C., Tremier, A., de Guardia, A., 2007. Coupling a respirometer and a pycnometer, to study the biodegradability of solid waste organic wastes during composting. Biosys. Eng. 97, 75-88.

Danielson R. E., Sutherland, P.L., 1986. Porosity, in: Klute, A. (Ed.), Methods of soil Analysis, Part 1. Physical and Mineralogical Methods. American Society of Agronomy and Soil Science Society of America, Madison, Wisconsin, USA, pp. 443461.

Eftoda, G., McCartney, D., 2002. Correlating bench-scale FAS test to full scale windrow composting performance, in: Michel, F.C., Rynk, R.F., Hoiting, H.A.J. (Eds), Proceedings of the International Symposium Composting and Compost Utilization, Columbus, Ohio, USA, pp. 204-220.

Eftoda, G., McCartney, D., 2004. Determining the critical bulking agent requirements for municipal biosolids composting. Compost Sci. Util. 12, 208-218.

Epstein, E., 1997. The Science of Composting. Technomic Publishing Company Inc., Lancaster, Pennsylvania, USA.

Gea, T., Barrena, R., Artola, A., Sánchez, A., 2004. Monitoring the biological activity of the composting process: oxygen uptake rate (OUR), respirometric index (RI) and respiratory quotient (RQ).Biotechnol. Bioeng. 88, 520-527.

Hamelers, H.V.M., 1993. A theoretical model of composting kinetics, in: Hoitink, H.A.J., Keener, H.M. (Eds), Science and Engineering of Composting: Design, Environmental, Microbiological and Utilization Aspects. Renaissance Publications, Worthington, pp. $36-58$. 
Hamelers, M., Richard, T., 2001. The effect of dry matter on the composting rate: theoretical analysis and practical implications, in: Proceedings of the ASAE International Meeting, Sacramento, California, USA, paper number 01-7004, pp. 16.

Haug, R.T., 1993. The practical Handbook of Compost Engineering. Lewis Publishers, Boca Raton, Florida, USA.

Hsu, J., Lo, S., 1999. Chemical and spectroscopic analysis of organic matter transformations during composting of pig manure. Environ. Poll. 104, 189-196.

Jeris, J.S., Regan, R.W., 1973. Controlling environmental parameters for optimum composting. II. Moisture, free air space and recycle. Compost Sci. Util. 14, 8-15.

Klute, A., 1986. Methods of Soil Analysis: Physical and Mineralogical Methods, Part 1, second ed., American Society of Agronomy and Soil Science Society of America, Madison, Wisconsin, USA.

Kulcu, R., Yaldiz, O., 2007. Composting of goat manure and wheat straw using pine cones as a bulking agent. Bioresource Technol. 98, 2700-2704.

Kulcu, R., Sönmez, I., Yaldiz, O., Kaplan, M., 2008. Composting of spent mushroom compost, carnation wastes, chicken and cattle manures. Bioresource Technol. 99, $8259-8264$.

Liao, P., Vizcarra, A., Chen, A., 1993. Composting of separated solid swine manure. J. Environ. Sci. Health A28, 1889-1901.

Madejon, E., Díaz, M.J., López, R., Cabrera, F., 2002. New approaches to establish optimum moisture content for compostable materials. Bioresource Technol. 85, 73-78.

McCartney, D., Chen, H., 2001. Using a biocell to measure effect of compressive settlement on free air space and microbial activity in windrow composting. Compost Sci. Util. 9, 285-302. 
Michel, F., Pecchia, J., Rigot, J., Keener, H., 2004. Mass and nutrient losses during the composting of dairy manure amended with sawdust or straw. Compost Sci. Util. 12, 323-334.

Mohee, R., Mudhoo, A., 2005. Analysis of the physical properties of an in-vessel composting matrix. Powder Technol. 155, 92-99.

Oppenheimer, J.R., Martin, A.G, Walker L.P., 1997. Measurements for air- filled porosity in unsaturated organic matrices using a pycnometer. Bioresource Technol. 59, 241-247.

Pall, R., Mohsenin, N.N., 1980. A soil air pycnometer for determination of porosity and particle density. Trans. ASAE 23, 735-741.

Poulsen, T., Moldrup, P., 2007. Air permeability of compost as related to bulk density and volumetric air content. Waste Manage. Res. 25, 343-351.

Richard, T.L., Byung, T.K., 2003. Biodegradation impacts on fluid transport properties of organic porous media, in: Eiteman, M. (Ed), Proceedings of the institute of biological Engineering. IBE publications, Athens, Greece.

Richard, T.L., Veeken, A.H., Wilde, V.D., Hamelers, M., 2004. Air filled porosity and permeability relationships during solid-state fermentation. Biotechnol. Prog. 20, 13721381.

Rudrum, D., Rulkens, W., Hamelers, M., 2002. The effect of bed structure on composting start-up, in: Michel, F.C., Rynk, R.F., Hoiting, H.A.J. (Eds), Proceedings of the International Symposium Composting and Compost Utilization, Columbus, Ohio, USA, pp. 221-233.

Ruggieri, L. 2008. Composting organic wastes. Determination, monitoring and evolution of air filled porosity by air pycnometry. $\mathrm{PhD}$ dissertation thesis. Universitat Autònoma de Barcelona. 
Ruggieri, L., Gea, T., Artola, A.., Sanchez, A., 2008a. A Study on Air Filled Porosity Evolution in Sludge Composting. Int. J. Environ. Waste Manage., in press.

Ruggieri, L., Gea, T., Artola, A., Sanchez, A., 2008b. Influence of different co-substrates biochemical composition on raw sludge co-composting. Biodegradation 19, 403-415.

Schulze, K.L., 1962. Continuous Thermophilic Composting. Appl. Microbiol. 10, 108-122.

Singley, M.E., Higgins, A.J., Frumkin-Rosengau, M., 1982. Sludge composting and utilisation: A design and operating manual, New Jersey Agricultural Experiment Station, Cook College, Rutgers-The State University of New Jersey, New Brunswick, USA.

Sole-Mauri, F., Illa, J., Magrí, A., Prenafeta-Boldú, X., Flotats, X., 2007. An integrated biochemical and physical model for the composting process. Bioresource Technol. 98, 3278-3293.

Su, D., McCartney, D., Wang, Q., 2006. Comparison of Free Air Space Test Methods. Compost Sci. Util. 14, 103-113.

Tamari, S., 2004. Optimum design of the constant-volume gas pycnometer for determining the volume of solid particles. Measurement Sci. Technol. 15, 549-558.

Tarzaghi, K., Peck, R., Mesri, G., 1996. Soil Mechanics in Engineering Practice, third ed. John Wiley and Sons, New York, USA.

U.S. Department of Agriculture, U.S. Compost Council (U.S.C.C), 1997. Test Methods for the Examination of Composting and Compost. Edaphos International, Houston, Texas, USA.

U.S. Department of Agriculture, U.S. Compost Council (U.S.C.C), 2001. Test Methods for the Examination of Composting and Compost. Edaphos International, Houston, Texas, USA. 
Vlyssides, A.G., Barampouti, E.M.P., Mai, S.Th., 2008. Physical characteristics of olive stone wooden residues: possible bulking material for composting process. Biodegradation $19,209-214$

Yu, S. Clark, O.G., Leonard, J.J., 2008. Influence of free air space on microbial kinetics in passively aerated compost. Bioresource Technol. in press: doi:10.1016/j.biortech.2008.06.051

Yue, B., Chen, T-B., Gao, D., Zheng, G-D., Liu, B., Lee, D-J., 2008. Pile settlement and volume reduction measurement during forced-aeration static composting. Bioresource Technol. 99, 7450-7457. 


\section{Legends to Figures}

Figure 1: Correlation analysis of AFPP (air filled porosity obtained by air pycnometry) versus $\mathrm{AFP}_{\mathrm{R}}$ (air filled porosity theoretically obtained according to Richard et al. (2004) approach) by several types of organic wastes: RS: raw sludge, FW: food waste, WC: wood chips, OFMSW: organic fraction of municipal solid waste, ADS: anaerobically digested sludge, ST: stalk and MS: mushroom substrate.

Figure 2: Correlation analysis of $\mathrm{AFP}_{\mathrm{P}}$ (air filled porosity obtained by air pycnometry) versus $\mathrm{BD}_{\mathrm{w}}$ (wet bulk density). DM denotes dry matter content. 
Figure 1

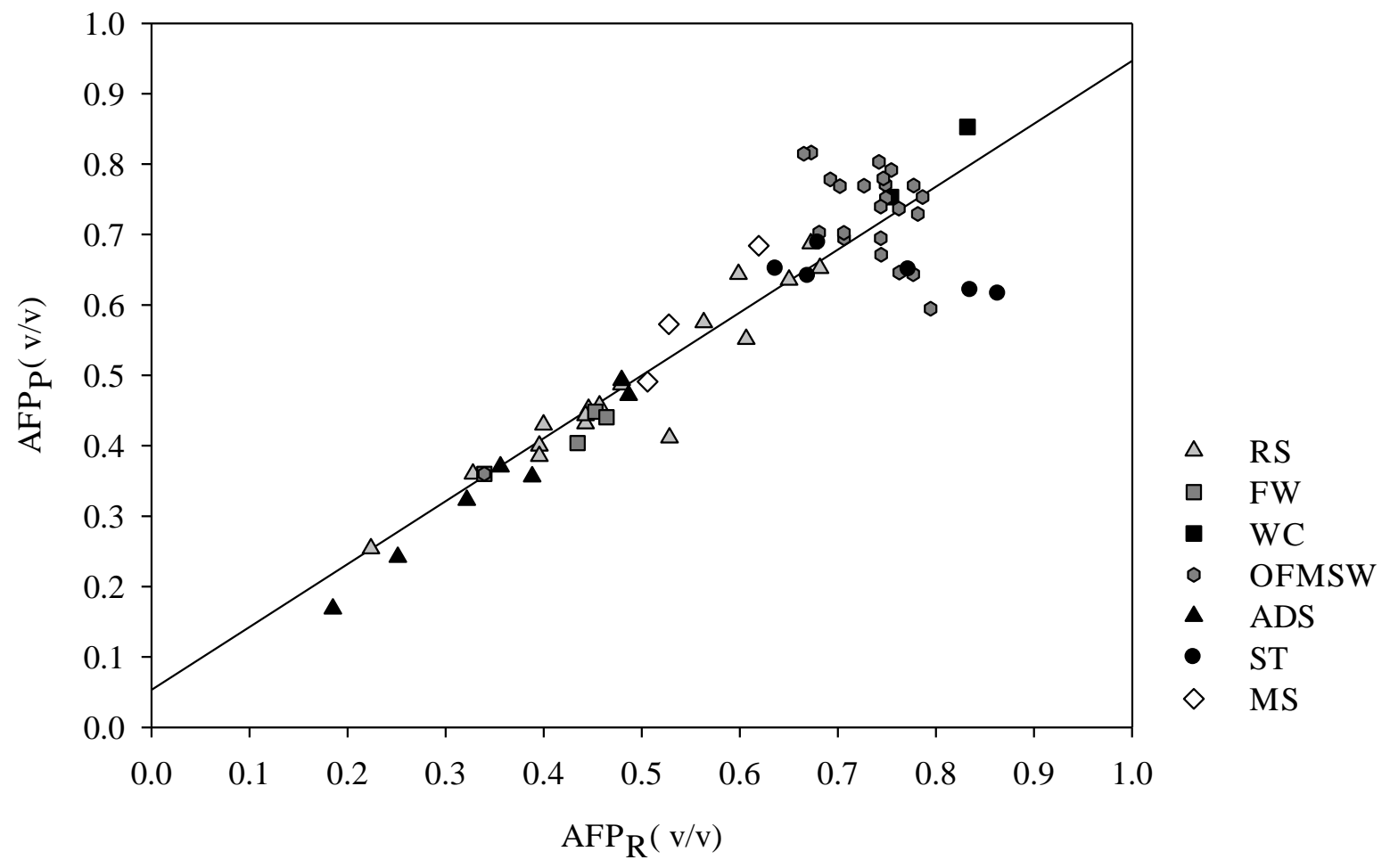


Figure 2

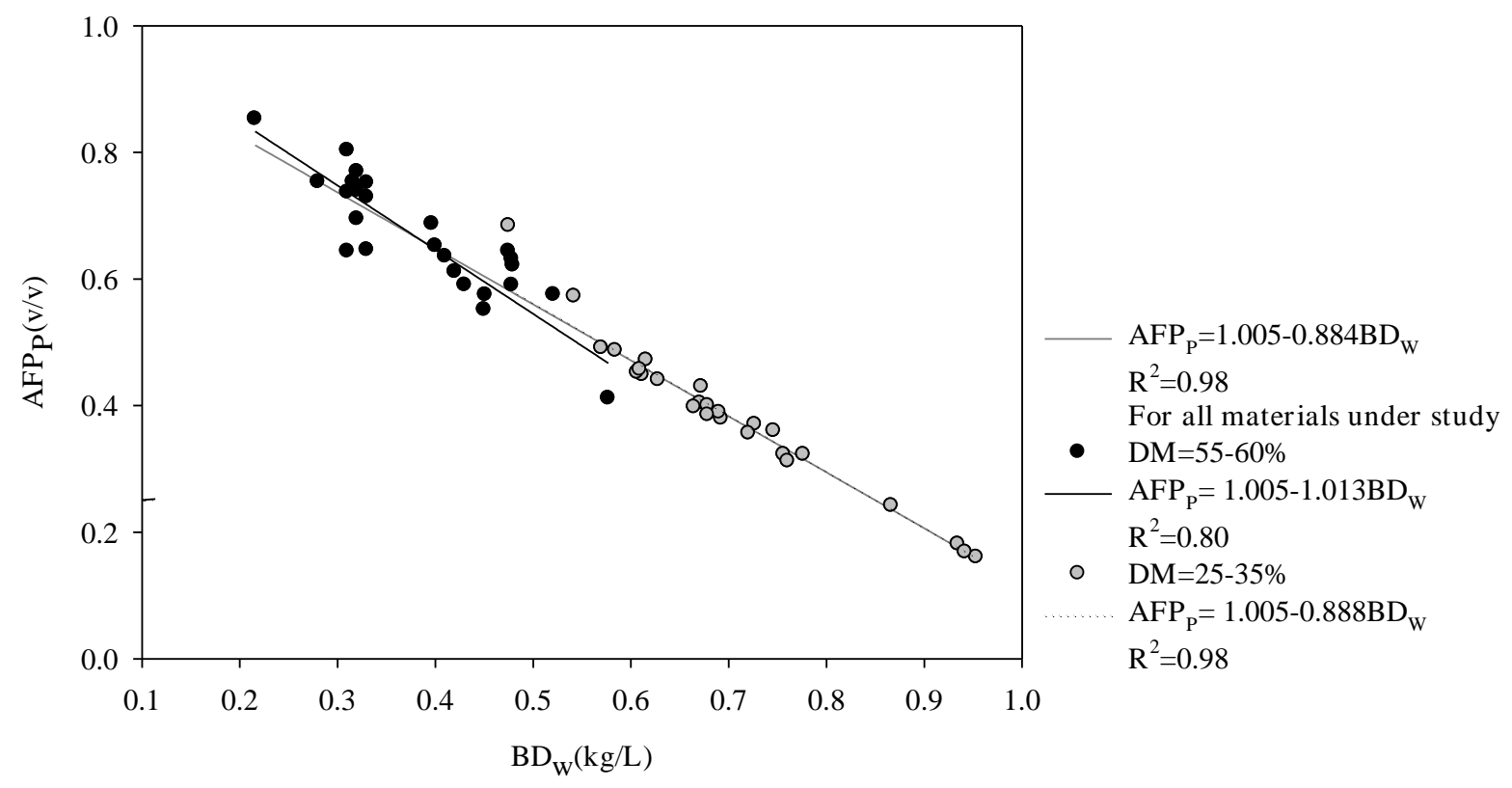


Table 1: Main characteristics of self-made pycnometers reported in literature.

\section{Reference}

\begin{tabular}{|c|c|c|c|c|c|c|}
\hline Characteristics & $\begin{array}{l}\text { Oppenheimer } \\
\text { et al. (1997) }\end{array}$ & Annan and White (1998) & $\begin{array}{l}\text { Agnew et al. (2002) } \\
\text { Agnew and Leonard } \\
\text { (2003) }\end{array}$ & Richard et al. (2004) & $\begin{array}{l}\text { Berthe et al. } \\
\text { (2007) }\end{array}$ & $\begin{array}{l}\text { Ahn et al. } \\
\text { (2008) }\end{array}$ \\
\hline Pycnometer material & PVC & - & PVC & steel & steel & steel \\
\hline Gas chamber volume, L & 1.0 & - & 31 & 22.5 & 25 & 22.4 \\
\hline Sample chamber volume, $\mathrm{L}$ & 1.0 & 1.5 & 25 & $22.5-45$ & 10 & 22.4 \\
\hline Calibration material & glass beads & steel ball bearings & water & water & water & - \\
\hline Initial pressure $(\mathrm{kPa})$ & $300,400,500$ & 52 & $70,140,172,200$ & 207 & $250-280$ & - \\
\hline
\end{tabular}


Table 2: Methods compared to air pycnometry by different authors and experimental materials used.

\begin{tabular}{|c|c|c|c|c|c|c|c|c|}
\hline \multirow[b]{2}{*}{ Characteristics } & \multicolumn{8}{|c|}{ Reference } \\
\hline & $\begin{array}{l}\text { Oppenheimer et } \\
\text { al. (1997) }\end{array}$ & $\begin{array}{l}\text { Su } \\
\text { et al. (2006) }\end{array}$ & $\begin{array}{l}\text { Eftoda and } \\
\text { McCartney } \\
\text { (2002) }\end{array}$ & $\begin{array}{l}\text { Annan and White } \\
\text { (1998) }\end{array}$ & $\begin{array}{l}\text { Agnew } \\
\text { et al. }(2003)\end{array}$ & $\begin{array}{l}\text { Richard } \\
\text { et al. }(2004)\end{array}$ & $\begin{array}{l}\text { Berthe } \\
\text { et al. }(2007)\end{array}$ & $\begin{array}{l}\text { Ahn } \\
\text { et al. (2008) }\end{array}$ \\
\hline $\begin{array}{l}\text { Experimental } \\
\text { materials used }\end{array}$ & $\begin{array}{l}\text { Sewage sludge, } \\
\text { dog food, wood } \\
\text { chips }\end{array}$ & $\begin{array}{l}\text { Straw, } \\
\text { woodchips, } \\
\text { biosolids, } \\
\text { wood } \\
\text { shavings }\end{array}$ & $\begin{array}{l}\text { Biosolids, } \\
\text { woodchips }\end{array}$ & $\begin{array}{l}\text { Sewage sludge, } \\
\text { wood chips }\end{array}$ & $\begin{array}{l}\text { MSW compost, } \\
\text { biosolids, manure } \\
\text { compost, gravel, } \\
\text { wood chips, } \\
\text { leaves, straw }\end{array}$ & $\begin{array}{l}\text { Manure, } \\
\text { straw }\end{array}$ & $\begin{array}{l}\text { MSW, agro-food } \\
\text { sludge, sewage } \\
\text { sludge, pine bark } \\
\text { chips }\end{array}$ & $\begin{array}{l}\text { Corn stalks, oat } \\
\text { straw, silage, wood } \\
\text { shavings, alfalfa } \\
\text { hay, soybean straw, } \\
\text { wheat straw }\end{array}$ \\
\hline $\begin{array}{l}\text { Compared } \\
\text { Methods }\end{array}$ & $\begin{array}{l}\text { Equation } \\
\text { proposed by Pall } \\
\text { and Mohsenin } \\
(1980)\end{array}$ & $\begin{array}{l}\text { Quick } \\
\text { Method } \\
\text { (U.S.C.C., } \\
\text { 2001), } \\
\text { Traditional } \\
\text { Soil Method } \\
\text { (Klute } \text { et al., } \\
\text { 1986) }\end{array}$ & $\begin{array}{l}\text { Water } \\
\text { Displacement } \\
\text { Method } \\
\text { (U.S.C.C., 1997), } \\
\text { Traditional Soil } \\
\text { Method (Klute } \text { et } \\
\text { al., 1986) }\end{array}$ & $\begin{array}{l}\text { Water pycnometer } \\
\text { (Singley, 1982), } \\
\text { Water Displacement } \\
\text { Method (U.S.C.C., } \\
\text { 1997), two } \\
\text { formulaic methods } \\
\text { proposed by } \\
\text { Schulze (1962) and } \\
\text { Haug (1993) }\end{array}$ & $\begin{array}{l}\text { Water pycnometry } \\
\text { (U.S.C.C., 1997), } \\
\text { Traditional Soil } \\
\text { Method (Klute et } \\
\text { al., 1986) }\end{array}$ & $\begin{array}{l}\text { Theoretical } \\
\text { AFP } \\
\text { (proposed by } \\
\text { authors) }\end{array}$ & $\begin{array}{l}\text { Theoretical AFP } \\
\text { (Richard et al., } \\
\text { 2004) }\end{array}$ & $\begin{array}{l}\text { Theoretical AFP } \\
\text { (Richard et al., } \\
\text { 2004) }\end{array}$ \\
\hline
\end{tabular}


Table 3: Theoretical expressions used for AFP determination.

\begin{tabular}{lll}
\hline Reference & Equation \\
\hline Epstein (1997) & $\mathrm{AFP}=100\left(1-\frac{\mathrm{BD}}{\mathrm{PD}}\right)$ & (Equation 8) \\
\hline $\begin{array}{l}\text { Richard } \\
\text { et al. (2004) }\end{array}$ & $\mathrm{AFP}_{\mathrm{R}}=1-\mathrm{BD}_{\mathrm{t}}\left(\frac{1-\mathrm{DM}}{\mathrm{D}_{\mathrm{w}}}+\frac{\mathrm{DMOM}}{\mathrm{PD}_{\mathrm{OM}}}+\frac{\mathrm{DM}(1-\mathrm{OM})}{\mathrm{PD}_{\mathrm{ash}}}\right)$ \\
\hline $\begin{array}{l}\text { Haug (1993) } \\
\mathrm{D}_{\mathrm{w}}: 1000\left(\mathrm{~kg} / \mathrm{m}^{3}\right), \mathrm{PD}_{\mathrm{OM}}: 2500\left(\mathrm{~kg} / \mathrm{m}^{3}\right), \mathrm{PD}_{\mathrm{ash}}: 1600\left(\mathrm{~kg} / \mathrm{m}^{3}\right)\end{array}$ & (Equation 9) \\
\hline $\begin{array}{l}\text { Madejon } \text { et al. } \\
\text { (2002) }\end{array}$ & $\mathrm{AFP}=1-\frac{\mathrm{BD}_{\mathrm{t}} \mathrm{S}_{\mathrm{m}}}{\mathrm{G}_{\mathrm{s}} \mathrm{D}_{\mathrm{w}}\left(\frac{\mathrm{BD}_{\mathrm{t}}\left(1-\mathrm{S}_{\mathrm{m}}\right)}{\mathrm{D}_{\mathrm{w}}}\right)}$ \\
\hline $\begin{array}{l}\text { Oppenheimer } \\
\text { et al. (1997) }\end{array}$ & $\mathrm{AFP}=100\left(1-\frac{\mathrm{BD}}{\mathrm{PD}}\right)(1-\mathrm{MC})$ & (Equation 10) \\
\hline
\end{tabular}

BD: bulk density (kg/L); PD: particle density (kg/L); DM: fraction of dry matter; OM: fraction of organic matter in dry basis; $D_{\mathrm{w}}$ : density of water $(\mathrm{kg} / \mathrm{L}) ; \mathrm{S}_{\mathrm{m}}$ : fraction of total solids in the mixture; $\mathrm{G}_{\mathrm{s}}$ : absolute specific gravity (dimensionless); MC: fraction of moisture content. 
Table 4: Empirical relationships of AFP with other parameters reported in literature. MSW denotes municipal solid waste. SS denotes sewage sludge.

\begin{tabular}{|c|c|c|}
\hline Authors & Equation & \\
\hline $\begin{array}{l}\text { Agnew and Leonard } \\
(2002)\end{array}$ & $\begin{array}{lr}\text { AFP }=-0.1479 B_{\mathrm{w}}+107.91 & \text { (woodchips) } \\
\text { AFP }=-0.1165 \mathrm{BD}_{\mathrm{w}}+96.95 & \text { (leaves) } \\
\mathrm{AFP}=-0.0891 \mathrm{BD}_{\mathrm{w}}+93.53 & (\text { straw) } \\
\mathrm{AFP}=-0.0906 \mathrm{BD}_{\mathrm{w}}+96.26 & (\text { straw-SS) } \\
\mathrm{AFP}=-0.0957 \mathrm{BD}_{\mathrm{w}}+111.22 & (\mathrm{MSW}) \\
\mathrm{AFP}=-0.0893 \mathrm{BD}_{\mathrm{w}}+103.3 & \text { (manure) }^{2}\end{array}$ & $\begin{array}{r}\mathrm{AFP}_{\mathrm{AL}}=100-0.0889 \mathrm{BD}_{\mathrm{w}} \\
(\text { Equation 13) }\end{array}$ \\
\hline $\begin{array}{l}\text { Liao et al. } \\
\text { (1993) }\end{array}$ & $\mathrm{AFP}_{\mathrm{L}}=0.91-2.46(\mathrm{MC})^{8.69}$ & (Equation 14) \\
\hline \multirow{2}{*}{$\begin{array}{l}\text { Mohee and Mudhoo } \\
\text { (2005) }\end{array}$} & $\begin{array}{l}\mathrm{AFP}_{\mathrm{MM}}=-0.0922 \mathrm{BD}_{\mathrm{w}}+101.84 \\
\left(\mathrm{BD}_{\mathrm{w}}=200-650 \mathrm{~kg} / \mathrm{m}^{3}\right)\end{array}$ & (Equation 15) \\
\hline & $\begin{array}{l}\mathrm{AFP}_{\mathrm{MM}}=-0.1713 \mathrm{BD}_{\mathrm{d}}+91.558 \\
\left(\mathrm{BD}_{\mathrm{d}}=100-300 \mathrm{~kg} / \mathrm{m}^{3}\right)\end{array}$ & (Equation 16) \\
\hline $\begin{array}{l}\text { McCartney and Chen } \\
\text { (2001) }\end{array}$ & $\mathrm{AFP}_{\mathrm{d}}=\mathrm{AFP}_{\infty}+\left(\mathrm{AFP}_{0}-\mathrm{AFP}_{\infty}\right)^{\mathrm{e}-\mathrm{bd}}$ & (Equation 17) \\
\hline
\end{tabular}

$\mathrm{BD}_{\mathrm{w}}$ : wet bulk density $(\mathrm{kg} / \mathrm{L}) ; \mathrm{BD}_{\mathrm{d}}$ : dry bulk density; $\mathrm{MC}$ : fraction of moisture content; $\mathrm{AFP}_{\mathrm{d}}$ : AFP at a depth d; $\mathrm{AFP}_{\infty}$ : AFP at maximum load; $\mathrm{AFP}_{0}$ : AFP at zero load; e: mathematical constant (2.71828); b: shape factor. 
Table 5: Physical characteristics and AFP values determined by air pycnometry $\left(\mathrm{AFP}_{\mathrm{P}}\right)$ of the composting materials under study.

\begin{tabular}{|c|c|c|c|c|}
\hline Material & $\underset{(\%)}{\operatorname{AFP}_{\mathbf{P}}}$ & $\begin{array}{c}\text { Bulk } \\
\text { Density } \\
(\mathrm{kg} / \mathrm{L})\end{array}$ & $\begin{array}{c}\text { Dry } \\
\text { Matter } \\
\text { (fraction) }\end{array}$ & $\begin{array}{l}\text { Organic Matter } \\
\text { (fraction, db) }\end{array}$ \\
\hline Food waste & 44.8 & 0.612 & 0.266 & 0.910 \\
\hline \multirow[t]{3}{*}{ + wood chips } & 40.4 & 0.671 & 0.398 & 0.915 \\
\hline & 44.0 & 0.628 & 0.372 & 0.917 \\
\hline & 36.0 & 0.746 & 0.272 & 0.793 \\
\hline \multirow[t]{2}{*}{ Wood chips } & 75.3 & 0.316 & 0.553 & 0.887 \\
\hline & 85.3 & 0.216 & 0.553 & 0.887 \\
\hline Raw sludge & 45.2 & 0.606 & 0.209 & 0.834 \\
\hline \multirow[t]{15}{*}{ + wood chips } & 45.7 & 0.609 & 0.240 & 0.651 \\
\hline & 48.7 & 0.584 & 0.240 & 0.651 \\
\hline & 43.0 & 0.672 & 0.260 & 0.842 \\
\hline & 40.0 & 0.679 & 0.267 & 0.849 \\
\hline & 38.5 & 0.679 & 0.267 & 0.849 \\
\hline & 43.1 & 0.626 & 0.267 & 0.849 \\
\hline & 44.3 & 0.626 & 0.267 & 0.849 \\
\hline & 36.0 & 0.709 & 0.127 & 0.834 \\
\hline & 68.7 & 0.397 & 0.439 & 0.912 \\
\hline & 64.4 & 0.475 & 0.360 & 0.760 \\
\hline & 65.2 & 0.400 & 0.498 & 0.846 \\
\hline & 55.1 & 0.450 & 0.301 & 0.813 \\
\hline & 63.5 & 0.410 & 0.350 & 0.800 \\
\hline & 41.1 & 0.577 & 0.431 & 0.787 \\
\hline & 57.5 & 0.521 & 0.377 & 0.767 \\
\hline $\begin{array}{l}\text { Organic fraction of municipal } \\
\text { solid waste }\end{array}$ & 36.0 & 0.746 & 0.272 & 0.793 \\
\hline \multirow[t]{14}{*}{ + wood chips } & 69.4 & 0.380 & 0.522 & 0.732 \\
\hline & 81.6 & 0.390 & 0.364 & 0.701 \\
\hline & 75.3 & 0.280 & 0.528 & 0.670 \\
\hline & 77.8 & 0.450 & 0.655 & 0.524 \\
\hline & 73.7 & 0.310 & 0.482 & 0.518 \\
\hline & 72.9 & 0.330 & 0.696 & 0.509 \\
\hline & 77.1 & 0.360 & 0.604 & 0.452 \\
\hline & 70.2 & 0.380 & 0.509 & 0.689 \\
\hline & 76.9 & 0.390 & 0.669 & 0.683 \\
\hline & 59.4 & 0.280 & 0.580 & 0.628 \\
\hline & 70.3 & 0.450 & 0.628 & 0.609 \\
\hline & 64.4 & 0.310 & 0.596 & 0.582 \\
\hline & 64.6 & 0.330 & 0.590 & 0.553 \\
\hline & 67.1 & 0.360 & 0.592 & 0.496 \\
\hline
\end{tabular}




\begin{tabular}{lllll} 
& 79.2 & 0.360 & 0.632 & 0.431 \\
69.5 & 0.320 & 0.454 & 0.719 \\
78.0 & 0.350 & 0.622 & 0.701 \\
80.3 & 0.310 & 0.378 & 0.701 \\
75.2 & 0.330 & 0.550 & 0.733 \\
76.9 & 0.410 & 0.622 & 0.714 \\
& 74.0 & 0.320 & 0.431 & 0.619 \\
& 81.5 & 0.450 & 0.566 & 0.656 \\
\hline Stalk & 77.0 & 0.320 & 0.682 & 0.687 \\
\hline 68.8 & 0.454 & 0.250 & 0.915 \\
& 65.1 & 0.508 & 0.277 & 0.916 \\
& 64.1 & 0.464 & 0.273 & 0.902 \\
& 61.5 & 0.190 & 0.283 & 0.919 \\
Mushroom substrate & 62.0 & 0.226 & 0.322 & 0.891 \\
& 65.0 & 0.324 & 0.351 & 0.631 \\
\hline Anaerobically digested & 68.4 & 0.475 & 0.409 & 0.507 \\
sludge + wood chips & 57.2 & 0.542 & 0.285 & 0.663 \\
& 49.1 & 0.570 & 0.292 & 0.639 \\
\hline & 24.2 & 0.866 & 0.281 & 0.518 \\
& 16.8 & 0.942 & 0.277 & 0.509 \\
& 37.0 & 0.727 & 0.243 & 0.592 \\
& 32.3 & 0.776 & 0.262 & 0.527 \\
& 47.2 & 0.616 & 0.341 & 0.503 \\
& 35.6 & 0.720 & 0.314 & 0.532 \\
& 49.3 & 0.608 & 0.310 & 0.601 \\
& 23.6 & 0.705 & 0.459 & 0.541 \\
\hline
\end{tabular}


Table 6: Correlation analysis of $\mathrm{AFP}$ (air filled porosity obtained by air pycnometry) versus other empirical approaches: $\mathrm{AFP}_{\mathrm{AL}}$, Equation 12; $\mathrm{AFP}_{\mathrm{L}}$, Equation 13; $\mathrm{AFP}_{\mathrm{MM}}$, Equation 14 (Table 4); $\mathrm{AFP}_{\mathrm{R}}$, Equation 8 (Table 3).

\begin{tabular}{lcc}
\hline Equation & $\mathrm{R}^{2}$ & Significance \\
\hline $\mathrm{AFP}_{\mathrm{P}}=0.1028+0.9353 \mathrm{AFP}_{\mathrm{AL}}$ & 0.894 & $\mathrm{p}<0.0001$ \\
$\mathrm{AFP}_{\mathrm{P}}=0.0102+0.0428 \mathrm{AFP}_{\mathrm{L}}$ & 0.548 & $\mathrm{p}<0.0001$ \\
$\mathrm{AFP}_{\mathrm{P}}=0.0844+0.9021 \mathrm{AFP}_{\mathrm{MM}}$ & 0.894 & $\mathrm{p}<0.0001$ \\
$\mathrm{AFP}_{\mathrm{R}}=0.0950+0.9926 \mathrm{AFP}_{\mathrm{AL}}$ & 0.988 & $\mathrm{p}<0.0001$ \\
\hline
\end{tabular}

